Jurnal Ilmiah Kesehatan Sandi Husada
https://akper-sandikarsa.e-journal.id/JIKSH
Volume 10| Nomor 2| Desember|2021
e-ISSN: 2654-4563 dan p-ISSN: 2354-6093
DOI 10.35816/jiskh.v10i2.631

Research article

\title{
Penerapan Asuhan Keperawatan Post Op Section Caesarea dalam
} Indikasi Preeklampsia Berat

Darmi Arda ${ }^{1}$, Hartaty Hartaty ${ }^{2}$

1,2 Departmen Keperawatan, Politeknik Sandi Karsa Makassar,

\begin{tabular}{|c|c|}
\hline Article Info & Abstract \\
\hline Article History: & $\begin{array}{l}\text { Pendahuluan; Sectio caesarea suatu tindakan medis yang } \\
\text { diperlukan untuk membantu persalinan yang tidak bisa dilakukan }\end{array}$ \\
\hline Received & secara normal akibat masalah kesehatan ibu atau kondisi janin \\
\hline 2021-07-01 & $\begin{array}{l}\text { yaitu salah satu faktor penyebab preeklamsia berat. Tujuan; } \\
\text { mengetahui penerapan asuhan keperawatan Post Op Section }\end{array}$ \\
\hline Accepted & $\begin{array}{l}\text { Caesarea dalam indikasi preeklampsia berat. Metode: yang } \\
\text { digunakan dalam penelitian ini adalah deskriptif, dengan }\end{array}$ \\
\hline 2021-09-02 & pendekatan studi kasus yang diambil diruangan nifas rumah sakit \\
\hline Published & $\begin{array}{l}\text { Swasta di Kota Makassar pada bulan Juni } 2020 \text {. Data diperoleh } \\
\text { dariibu pasien, perawat, tim kesehatan, catatan perkembangan, }\end{array}$ \\
\hline $2021-12-31$ & $\begin{array}{l}\text { dan catatan kesehatan. Hasil: menunjukkan nyeri merupakan } \\
\text { masalah utama yang muncul pada pasien Post Op Section }\end{array}$ \\
\hline & $\begin{array}{l}\text { Caesarea. Setelah dilakukan tindakan keperawatan nyeri dapat } \\
\text { teratasi. Kesimpulan; bahwa dari penanganan nyeri yang } \\
\text { dilakukan dengan hasil nyeri pasien dapat teratasi dipengaruhi } \\
\text { oleh pemberian manajemen nyeri yang dikembangkan. }\end{array}$ \\
\hline
\end{tabular}

Keywords:

Post-op SC;

Preeclampsia Berat;

Nyeri;

Introduction; Sectio Caesarea is a medical action needed to assist in childbirth that cannot be carried out normally due to maternal health problems or the condition of the fetus, which is a factor that causes severe preeclampsia. Aim; knowing the application of Post Op Sc nursing care in indications of severe preeclampsia. Methods: The method used in this research is descriptive, with a case study approach taken in the postpartum ward of a private hospital in Makassar City in June 2020. Data were obtained from the patient's mother, nurses, health team, progress notes, and health records. Results: showing pain is the main problem that arises in Post Op Section Caesarea patients. After nursing actions, pain can be resolved. Conclusion; that from pain management carried out with the patient's pain results can be overcome influenced by the provision of developed pain management.

\begin{tabular}{ll}
\hline Corresponding author & $:$ Darmi Arda \\
Email & $:$ darmiarda5@gmail.com
\end{tabular}

\section{Pendahuluan}

Persalinan merupakan proses yang terjadi dimulai dari terbukanya leher rahim hingga proses keluarnya bayi serta plasenta melalui jalan lahir (rahim). Persalinan dibagi dalam tiga jenis, 
yaitu: persalinan normal, persalinan buatan, dan persalinan anjuran/ induksi. Persalinan normal adalah proses persalinan yang melalui vagina (per vaginam). Persalinan anjuran/induksi terjadi setelah pemecahan ketuban, pemberian pitocin atau prostaglandin, sedangkan persalinan buatan adalah persalinan dengan bantuan tenaga dari luar misalnya dengan forceps atau seksio sesarea (Pamilangan et al., 2020). Sectio caesarea merupakan tindakan medis yang diperlukan untuk membantu persalinan yang tidak bisa dilakukan secara normal akibat masalah kesehatan ibu atau kondisi janin. Tindakan ini diartikan sebagai pembedahan untuk melahirkan janin dengan membuka dinding perut dan dinding uterus atau vagina atau suatu histerotomi untuk melahirkan janin dari dalam rahim (Kristensen et al., 2018). Angka kelahiran di Indonesia masih tinggi dan kira-kira $15 \%$ dari seluruh wanita hamil mengalami komplikasi dalam persalinan. Hal ini membutuhkan penanganan khusus selama persalinan (Novi Frima Lestari et al., 2019).

Menurut Guyton dalam (Wahyu, 2018) bahwa Sectio caesarea adalah salah satu bentuk pengeluaran fetus melalui sebuah irisan pembedahan yang menembus abdomen seorang ibu (laparotomy) dan uterus (hiskotomy) untuk mengeluarkan satu bayi atau lebih. Sectio caesarea adalah suatu tindakan untuk melahirkan bayi dengan berat diatas 5000 gram, melalui sayatan pada dinding uterus yang masih utuh. Angka persalinan dengan metode sesar telah meningkat di seluruh dunia dan melebihi batas kisaran 10\%-15\% yang direkomendasikan World Health Organization (WHO) dalam upaya penyelamatan nyawa ibu dan bayi. Amerika Latin dan wilayah Karibia menjadi penyumbang angka metode sesar tertinggi yaitu 40,5 persen, diikuti oleh Eropa (25\%), Asia (19,2\%) dan Afrika (7,3\%)2. Di Indonesia berdasarkan hasil Riset Kesehatan Dasar (Riskesdas) tahun 2018 menunjukkan prevalensi tindakan sesar pada persalinan adalah 17,6 persen, tertinggi di wilayah DKI Jakarta $(31,3 \%)$ dan terendah di Papua $(6,7 \%)$ (Sulistianingsih \& Bantas, 2019).

Data dari hasil Survey Kesehatan Dasar tahun 2013 menunjukan bahwa kejadian persalinan dengan tindakan SC di Indonesia mencapai 9,8 \% dari jumlah persalinan. Jika dibandingkan dengan data dari hasil SDKI (Survei Demografi Dan Kesehatan Indonesia) tahun 2017 menunjukkan bahwa angka kejadian persalinan dengan tindakan SC sebanyak 17\% dari total jumlah kelahiran di fasilitas kesehatan. Hal ini berarti terjadi peningkatan angka persalinan dengan metode SC. Sebanyak 18,8\% persalinan SC dilakukan karena KPD dan 13,6\% disebabkan oleh karena faktor lain, diantaranya yaitu kelainan letak pada janin, PEB dan riwayat SC. Menurut (Mustar, 2020) bahwa terdapat hubungan antara pengetahuan dan pendidikan ibu hamil dan ibu bersalin dengan tradisi dalam menghadapi kehamilan dan persalinan. Berdasarkan uraian tersebut, maka tujuan penelitian ini adalah mengetahui dan melaksanakan penerapan asuhan keperawatan Post Op Section Caesarea dalam indikasi preeklampsia berat.

\section{Metode}

Metode yang digunakan dalam penelitian ini adalah deskriptif, dengan pendekatan studi kasus. Informan pada peneltiian ini adalah pasien yang berkunjung ke Rumah Sakit dengan fokus gangguan rasa aman nyaman nyeri, pasien post op Post Op Section Caesarea. Peneltiian dilaksanakan pada bulan Juni 2020 di Rumah Sakit X di Kota Makassar. Pengumpulan data dilakukan dengan cara; wawancara, observasi dan pemeriksaan fisik. Penyajian dibuat oleh peneliti dalam bentuk teks naratif, dimana data dalam studi kasus dibuat dalam suatu kalimat yang menceritakan rangkaian kejadian dan membandingkan peneliti sebelumnya. Penyajian data dapat disertai dengan ungkapan secara verbal dari subyek studi kasus yang merupakan data pendukung.

\section{Hasil Dan Pembahasan}

Hasil penelitian menunjukan bahwa pengkajian nyeri merupakan keluhan utama pada saat dilakukan pengkajian. Data subyektif yang mendukung keluhan tersebut adalah pasien mengatakan nyeri pada luka post op sc di bagian bawah abdomen, skala 4 (sedang), nyeri 
bertambah jika banyak bergerak. Sedangkan data objektif yang mendukung keluhan tersebut adalah pasien tampak meringis dan nyeri dirasakan karena luka Post Op SC.

Pengkajian adalah upaya mengumpulkan data secara lengkap dan sistematis untuk dikaji dan di analisis sehingga masalah kesehatan dan keperawatan yang di hadapi pasien baik fisik, mental, sosial maupun spiritual dapat ditentukan tindakan yang harus diambil untuk mengatasi masalah (Hia, 2019). Menurut (Wiratama, 2019) bahwa proses pengkajian mencakup: pengumpulan data, penyusunan data, validasi data, pencatatan data. Pengumpulan data adalah alat utama dalam pengkajian awal pasien dan merupakan proses yang kontinyu untuk memperoleh informasi yang diperlukan untuk asuhan keperawatan. Nyeri yang dirasakan klien merupakan gejala sisa yang diakibatkan oleh operasi sectio caesarea yang dilakukan. Pada umumnya pasien post sectio caesarea mengeluh nyeri pada daerah luka bekas operasi. Sekitar $60 \%$ klien menderita nyeri hebat, 25\% nyeri sedang dan 15\% nyeri ringan (Ramandanty, 2019). Menurut (Suprapto, 2021) bahwa salah satu penyebab terjadinya infeksi nosokomial atau nyeri adalah penerapan standar operasional prosedur, baik yang dilaksanakan dengan baik atau tidak oleh perawat.

Bahwa hasil penelitian diagnosa keperawatan menunjukan nyeri akut berhubungan dengan agen pencedera fisik (pembedahan). Dimana diagnosa keperawatan adalah langkah kedua dari proses keperawatan yang menggambarkan penilaian klinis tentang respon individu, keluarga, kelompok maupun masyarakat terhadap permasalahan kesehatan baik aktual maupun potensial. Dimana perawat mempunyai lisensi dan kompetensi untuk mengtasinya.

Menurut (Ramandanty, 2019) bahwa diagnosa keperawatan yang muncul pada klien post sectio caesarea yaitu nyeri akut, gangguan pola tidur, gangguan mobilitas fisik, konstipasi, menyusui tidak efektif, defisit pengetahuan tentang teknik menyusui, defisit pengetahuan tentang perawatan diri, ganggaun proses keluarga, ansietas, resiko infeksi. Menurut Nuratif, Kusuma, dalam (Agustin, 2019) diagnosa keperawatan post Sectio Caesarea dengan indikasi pre-eklamsia berat terbagi menjadi; Nyeri akut b/d injury fisik (pembedahan,trauma jalan lahir,episiotomi), Hambatan mobilitas fisik b/d efek anestesi,nyeri, Ansietas b/d perubahan dan fungsi peran, Kurangnya perawatan diri b/d nyeri, Risiko tinggi infeksi b/d trauma jaringan/luka bekas operasi.

Bahwa hasil penelitian menunjukan intervensi keperawatannyeri akut berhubungan dengan agen pencedera fisik (pembedahan). Tujuan setelah dilakukan tindakan keperawatan $2 \times 24$ jam diharapkan nyeri dapat di kontrol dengan kriteria hasil ekspresi wajah tidak meringis dan pasien mengatakan nyeri sudah dapat di kontrol. Intervens; observasi TTV (tanda-tanda vital), kaji karakteristik nyeri, ajarkan teknik relaksasi nafas dalam dan kolaborasi pemberian obat analgetik.

Menurut (Wijiyanti, 2010) bahwa nyeri paskabedah merupakan masalah pada penderita yang mengalami pembedahan. Nyeri yang tidak tertangani dengan baik dapat menimbulkan gangguan pada sistem pernafasan, kardiovaskuler, muskuloskeletal dan mobilitas pasien. Nyeri dapat dikurangi dengan manajemen nyeri farmakologi dan atau nonfarmakologi. EFT atau tapping dapat menjadi salah satu pengobatan non farmakologis sebagai terapi komplementer untuk mengurangi nyeri pasca operasi SC (Latifah \& Ramawati, 2018). Tahap implementasi didasarkan pada rencana yang telah disusun oleh penulis bersama klien dan keluarga. Dalam mengevaluasi proses keperawatan pada klien dengan gastritis selalu mengacu pada tujuan pemenuhan kebutuhan klien. Hasil evaluasi yang dilakukan selama tiga hari menunjukkan bahwa semua permasalahan dapat diatasi (Suprapto, 2020).

Hasil penelitian menunjukkan bahwa implementasi keperawatan telah dilakukan tindakan keperawatan mengobservasi TTV dengan hasil tekanan darah 140/90 mmHg, nadi 92x/menit, suhu $36,2^{\circ} \mathrm{C}$, pernapasan 20x/menit, mengkaji karakteristik nyeri dengan hasil; Post Op SC, teriris-iris, abdomen Bawah, 4 (Sedang), Jika banyak bergerak, nyeri dirasakan dalam waktu tidak menentu, mengajarkan teknik relaksasi napas dalam dengan hasil pasien mengatakan masih 
nyeri setelah diajarkan teknik relaksasi nafas dalam dan tindakan pentalaksaaan pemberian obat analgetik.

Menurut (Ngurah, 2020) bahwa dengan memberikan pengetahuan pada pasien, khusunya yang mengalami gangguan rasa nyaman (nyeri) sehingga mampu menerapkan teknik relaksasi nafas dalam baik secara mandiri. Bahwa dalam implementasi sebagian benar telah sesuai dengan rencana yang sudah di terapkan. Kerjasama antar tim kesehatan dan pasien atau keluarga sangat diperlukan untuk keberhasilan asuhan keperawatan pada klien, sehingga masalah keperawatan pada klien mengenai nyeri akut sebagian masalah teratasi hingga tuntas (Supami, 2020). Menurut (Lestari, 2019) bahwa teknik relaksasi benson efektif dapat mengurangi nyeri pada ibu dengan post sectio caeserea.

Hasil penelitian menunjukan bahwa evaluasi keperawatan mengacu kepada kriteria tujuan. Evaluasi masalah keperawatan dilakukan dengan melihat perkembangan kondisi atau respon dari pasien. Diagnosa Nyeri akut yang ditemukan pada kasus dapat teratasi pada hari kedua pemberian implementasi. Pada hari pertama pemberian implementasi yang menghasilkan evaluasi pada jam 17.30 wita. Data subyektif yaitu pasien mengatakan nyeri pada luka post op sc dengan skala nyeri 4 (sedang). Data objektif yaitu keadaan umum lemah, TTV= tekanan darah 140/90 $\mathrm{mmHg}$, nadi $92 \mathrm{x} / \mathrm{menit}$, suhu $36,2^{\circ} \mathrm{c}$, pernapasan 20x/menit, ada nyeri tekan abdomen bawah, tampak meringis. Masalah belum teratasi dan harus melanjutkan intervensi. Pada hari kedua pemberian implementasi yang menghasilkan evaluasi pada jam 13.00 wita. Data subyektif yaitu pasien mengatakan nyeri yang dirasakan berkurang dan dapat di kontrol. Data objektif yaitu $\mathrm{TTV}=$ tekanan darah $130 / 80 \mathrm{mmHg}$, nadi $96 \mathrm{x} /$ menit, suhu $36^{\circ} \mathrm{C}$, pernapasan $24 \mathrm{x} /$ menit. Masalah teratasi dan intervensi dihentikan.

Menurut (Pingky Agustia Zakaria, 2019) bahwa asuhan keperawatan dari hasil studi kasus ini menunjukan tidak terdapat kesenjangan bahwa intensitas nyeri pasien mengalami penurunan, dengan kata lain teknik aromaterapi lemon efektif untuk menurunkan intensitas nyeri pada pasien post sectio caesarea, perlu konsistensi perawat dalam melakukan teknik aromaterapi lemon untuk menurunkan intensitas nyeri. Evaluasi nyeri akut terkontrol. Managemen nyeri relaksasi benson efektif dalam penanganan masalah nyeri akut berhubungan dengan agen cidera fisik (Astutiningrum \& Fitriyah, 2019). Menurut (Arda et al., 2020) bahwa mengoptimalkan tatalaksana pada asuhan keperawatan pada pasien merupkan kewajiban bagi perawat.

\section{Simpulan Dan Saran}

Bahwa masalah nyeri yang dirasasakan pasien teratasi dengan pemberian implementasi ditandai dengan nyeri yang dirasakan berkurang dan dapat di kontrol. Studi kasus ini sebagai gambaran keluarga untuk mampu merawat pasien Post Op Section Caesarea dalam indikasi preeklampsia berat dengan masalah nyeri akut dan program peningkatan kualitas pelayanan kesehatan.

\section{Daftar Rujukan}

Agustin, L. I. A. (2019). Karya Tulis Ilmiah Asuhan Keperawatan Pada Ny .” M ” Dengan Diagnosa Medis Post Sc Dengan Indikasi Pre Eklamsia Karya Tulis Ilmiah Asuhan Keperawatan Pada Ny ." M " Dengan Diagnosa.

Arda, D., Hartaty, H., \& Hasriani, H. (2020). Studi Kasus Pasien dengan Diare Rumah Sakit di Kota Makassar. Jurnal Ilmiah Kesehatan Sandi Husada, 11(1), 461-466.

Astutiningrum, D., \& Fitriyah, F. (2019). Penerapan Tehnik Relaksasi Benson untuk Menurunkan Nyeri pada Pasien Post Sectio Caesarea. Proceeding of The URECOL, 934-938.

Hia, Y. (2019). Tahap-Tahap Pengkajian Dalam Proses Keperawatan Dirumah Sakit.

Kristensen, J., Maeng, M., Mortensen, U. M., Berg, J., Rehling, M., \& Nielsen, T. T. (2018). Lack of cardioprotection from metabolic support with glutamine or glutamate in a porcine 
Darmi Arda, dkk. Penerapan Asuhan Keperawatan Post Op

coronary occlusion model. Scandinavian Cardiovascular Journal, 39(1), 115-120. https://doi.org/10.1080/14017430510009078

Latifah, L., \& Ramawati, D. (2018). Intervensi Emotional Freedom Technique (Eft) Untuk Mengurangi Nyeri Post Operasi Sectio Caesaria (Sc). Indonesian Nursing Journal Of Education And Clinic (INJEC), 1(1), 53-60.

Lestari, N. F. (2019). Analisis praktik klinik keperawatan penurunan nyeri pada pasien post op sc. UNIVERSITAS PERINTIS INDONESIA.

Mustar, M. (2020). Faktor yang Berhubungan dengan Tradisi Masyrakat dalam Menghadapi Kehamilan dan Persalinan Di Desa Welado. Jurnal Ilmiah Kesehatan Sandi Husada, 11(1 SE-Articles). https://doi.org/10.35816/jiskh.v11i1.342

Ngurah, G. (2020). Gambaran Asuhan Keperawatan Pada Pasien Hipertensi Dengan Gangguan Kebutuhan Rasa Nyaman Nyeri. JURNAL GEMA KEPERAWATAN, 13(1).

Novi Frima Lestari, N. F. L., Andriani, N. Y., Kep, M., \& Mat, S. P. K. (2019). Analisis praktik klinik keperawatan penurunan nyeri pada pasien post op sc. STIKes PERINTIS PADANG.

Pamilangan, E. D., Wantani, J. J. E., \& Lumentut, A. M. (2020). Indikasi Seksio Sesarea di RSUP Prof. Dr. RD Kandou Manado Tahun 2017 dan 2018. E-CliniC, 8(1).

Pingky Agustia Zakaria, P. (2019). Asuhan Keperawatan Pada Pasien Post Sectio Caesarea (Sc) Dalam Pemenuhan Kebutuhan Gangguan Rasa Aman Nyaman. STIKes Kusuma Husada Surakarta.

Ramandanty, P. F. (2019). Asuhan Keperawatan Pada Ibu Post Operasi Sectio Caesarea Di Ruang Mawar Rsud Aw Sjahranie Samarinda.

Sulistianingsih, A. R., \& Bantas, K. (2019). Peluang Menggunakan Metode Sesar Pada Persalinan Di Indonesia ( Analisis Data Sdki Tahun 2017 ). Jurnal Kesehatan Reproduksi, 9(2), 125133. https://doi.org/10.22435/kespro.v9i2.2046.125-133

Supami, S. (2020). Ibu Post Partum Sc (Sectio Caesarea) Dengan Masalah Keperawatan Nyeri Akut. STIKES Panti Waluya Malang.

Suprapto, S. (2020). Penerapan Asuhan Keperawatan Pada Gangguan Sistem Pencernaan "Gastritis." Jurnal Ilmiah Kesehatan Sandi Husada, 11(1 SE-Articles). https://doi.org/10.35816/jiskh.v11i1.211

Suprapto, S. (2021). Nurse Compliance in Implementing Post Op Wound Care Standard Operating Procedures. Media Keperawatan Indonesia, 4(1), 16-21.

Wahyu, A. (2018). Efektifitas Relaksasi Benson terhadap penurunan nyeri pasien pasca Sectio Caesarea. Jurnal Keperawatan Silampari, 2(1), 236-251.

Wijiyanti, F. (2010). Efektivitas Terapi Spiritual Emotional Freedom Technique (SEFT) terhadap Penurunan Intensitas Nyeri pada Pasien Paska-operasi Sectio Caesaria. Universitas Diponegoro.

Wiratama, P. (2019). Langkah Awal Pengkajian Dalam Proses Keperawatan. 